\title{
Gd-GLU toward NMR imaging: synthesis, characterization and breast cell uptake assay"
}

\author{
Tarcisio Passos Ribeiro de Campos ${ }^{\circledR 1 *}$, Ilza Dalmazio², Rodiney Augusti ${ }^{\circledR 3}$, \\ Iassudara Garcia Almeida ${ }^{1 \mathrm{~s}}$
}

\begin{abstract}
${ }^{1}$ Nuclear Engineering Department, Federal University of Minas Gerais, Belo Horizonte, MG, Brazil, ${ }^{2}$ Center of Development of the Nuclear Technology, CDTN, Universidade Federal de Minas Gerais, Belo Horizonte, MG, Brazil, ${ }^{3}$ Chemistry Institute, Federal University of Minas Gerais, Belo Horizonte, MG, Brazil
\end{abstract}

\begin{abstract}
Breast cancer cell uptake of Gd-metal is investigated based on the formation of coordinate compounds of gadolinium and glucose (Glu) molecules in solution. The hypothesis is that glucose helps Gdinternalization by complex formations constituted of $\mathrm{Gd}^{3+}$ coordinate to $\mathrm{m}$-glucose molecules, whose valence was complemented by $\mathrm{Cl}^{-}$anions. Such a proposal is an insight toward a metabolic-dependent contrast-agent for cancer and inflammation in magnetic resonance image. A solution was prepared based on anhydrous d-glucose and gadolinium chloride (Gd-Glu). Uptake assays for MDA-MB-231(c231) cells were elaborated collecting incubated c231-cells with Gd-Glu and measuring metal-uptake and their concentrations by Nuclear Activation Analysis (NAA). The ionic solution was studied using Direct-Infusion Electrospray Ionization Mass-Spectrometry (ESI-MS) to identify Gd-Glu interactions. Means and standard deviations of Gd-masses were $13.3 \pm 0.8$ and $12.5 \pm 0.7 \mu \mathrm{g}$, at $361.5 \mu \mathrm{g}$ of $\mathrm{Gd}$ in $3 \mathrm{~mL} \mathrm{Gd-Glu/PBS}$ solution, in times of 30-50 min, equivalent to the concentrations of $13404 \pm 2104$ and $11347 \pm 2742 \mu \mathrm{g} . \mathrm{g}^{-1}$ in dried cells. Such values were statistically higher than the control with metal presence. ESI-MS demonstrated the m/z-signals at 516, 552, 696, 923, attributed to positively loaded-species containing $\mathrm{Glu}, \mathrm{Gd}^{+3}$ and $\mathrm{Cl}^{-}$. In conclusion, Gd-internalization was increased in aqueous solution due to the gadolinium-glucose coordination. Such findings drive the research to MRI with Gd-Glu complexes.
\end{abstract}

Keywords: Glucose. Gadolinium. Breast cancer. In vitro uptake. MDA-MB-231.

\section{INTRODUCTION}

The viability of providing a diagnosis with contrastagents, supported by nuclear magnetic resonance images and guided to tissues that present high glucose metabolism, is attractive and justifies the search for molecular-tracers as an agent for screening small high metabolic sites. Such procedure excludes radionuclides; therefore, there would not be radiotoxicity and radioprotection involvements. Considering that such molecules being sugar-types linked to paramagnetic atoms of the group of the lanthanides, it is

\footnotetext{
*Correspondence: T. P. R. Campos. Universidade Federal de Minas Gerais, Av. Antonio Carlos, 6627, Prédio 4, Sala 2285. Phone: 34096691. E-mail: tprcampos@pq.cnpq.br, tprcampos@yahoo.com.br.

\#Study developed in Radiobiology and Radiochemistry laboratory of Nuclear Engineering Department, Institute of Chemistry at Federal University of Minas Gerais (UFMG), Belo Horizonte, MG, Brazil; and in Radiochemical Laboratory in the Centro de Desenvolvimento da Tecnologia Nuclear (CDTN), CNEN. $\$$ at the period of the research.
}

possible that such chemical compounds have no chemical toxicity due to their non-toxic constituents. Consequently, there would be no restriction of its application as a contrast agent. In addition, such protocols may generate medical information that can be able to overlap the diagnosis with PET - Positron Emission Tomography with fluordeoxyglucose, reproducing similar medical analyses. In turn, there would be a perspective to have MRI taking care of the diagnosis of some diseases based on the evaluation of metabolic-sugar uptake as in inflammations, small tumors or metastasis, with a lesser cost and increased safety.

As a contrast agent, the gadolinium element is of the group of the lanthanides, sixth period, that presents the following isotopes, with respective isotopic abundance: ${ }^{152} \mathrm{Gd}, 0.20 \% ;{ }^{154} \mathrm{Gd}, 2.18 \% ;{ }^{155} \mathrm{Gd}, 14.80 \%$; ${ }^{156} \mathrm{Gd}, 20.47 \% ;{ }^{157} \mathrm{Gd} 15.65 \% ;{ }^{158} \mathrm{Gd}, 24.84 \%$; and ${ }^{160} \mathrm{Gd}, 21.86 \%$. (Chart of Nuclides, 2017; Lide, 2009) 
The nuclides of an odd number of mass present high paramagnetic properties providing a high contrast signal in NMR images or spectrometry (Shah et al., 2006). Gadolinium atoms have seven unpaired electrons, hence hold high paramagnetism. Currently, there are nine different Gd-based contrast-agents for MRIimaging clinical cases, commercially available. After administration of all these agents, gadolinium presence occurs in extracellular space, in the hepatocyte-specific region - also extracellular, and in the whole blood pool. There is no case of Gd ion cell internalization, provided by an MRI agent (Guglielmo, Mitchell, Gupta, 2014). In the present state of the art, Gd cell internalization has been investigated to improve MRI-diagnostic specificity and sensitivity. DTPA-Gd targeting vascular endothelial growth factor receptor or any other receptor-mediators and magnetic coated Gd-nanoparticles can be considered as pharmaceutical agents addressing cell internalization, with suitable contrasting properties (Liu et al., 2017; Rammohan et al., 2017). Indeed, cancer-cell uptake can enhance the tumor signal intensity and prolong the diagnostic time.

As well known, metabolism is altered in various diseases such as cancer due to the proliferative status of the malignant cells. Walburg, Wind and Negelein (1927), postulated the respiratory process changes in cancer cells toward aerobic glycolysis (AG) method of energy production, named the Warburg-effect (Walburg, Wind, Negelein, 1927). This effect describes how the abnormal cancerous-cell provides energy from respiration following the AG process in preference to the usual oxidative phosphorylation (OP) (Ngo et al., 2015; Justus, Sanderlin, Yang, 2015; Wise, Thompson, 2010; Gatenby, Gillies, 2004). Cancer-cells use a larger amount of Glu than normal cells; therefore, breast cancer cell brings high Glu to its cytoplasm. AG creates only two ATP molecules, while OP creates up to 36 ATP molecules, per Glu molecule. It may explain why cancer-cell needs so large amount of Glu as energy-supplier for a fast growing and thus more needs of energy-sources in comparison to the normal tissue (Ngo et al., 2014).

Glucose can be taken into cells by active or passive processes. Passive as a facilitated diffusion is supported by glucose-transporters (named GLUT), in which entropy and kinetic energy carry the Glus along the gradient concentration. While, active transport is going against the gradient and involves energy consumption, using ATP hydrolysis (primary) or electrochemical gradient (secondary). GLUT family presents 14 types enclosed into three major classes defined by the substrate selectivity and the sequence homology (Manolescu et al., 2007; Uldry,
Thorens, 2004). In general, cancerous cells present an increase in GLUT by overexpressing GLUTs specifically, knowing up to now: GLUT1 in breast, colorectal, lung, and ovarian carcinoma (Cantuaria et al., 2001; Haber et al., 1998; Ogawa, Inoue, Koide, 1997; Younes et al., 1995), GLUT12 in breast cancer (Rogers et al., 2002), or GLUT3 in lung, ovarian and gastric cancers (Younes et al., 1997), meningioma (Van de Nes et al., 2015), squamous cell carcinoma (Abdou, Eldien, Elsakka, 2015), glioblastoma (Bache et al., 2015), among others. The breast carcinoma cell lines MCF-7 and MDA-MB-231 (c231) possess high amounts of GLUT5 exhibiting high rates of glucose and fructose transport (Zamora-Leon et al., 1996). The high uptake of Glu by their GLUT-transporters play a role in the metabolism of $\mathrm{c} 231$ cancerous cells.

At this stage of research development, the present paper addresses the synthesis of Gd-Glu complexes in aqueous solution, their characterization by Electrospray Ionization Mass Spectrometry, and the in vitro tests. The hypothesis is that cell uptake occurs due to Gd metal complexation with glucose molecules in solution, holding it at a prolonged time up to $50 \mathrm{~min}$ which may provide a possible MR imaging.

\section{MATERIAL AND METHODS}

\section{Material}

T-75 and T-25 flasks were employed for cell cultivation. Polyethylene vials of $1.0 \mathrm{~mL}$ were also employed, suitable for neutron activation analysis (NAA). Controlled-speed centrifuges; humid atmosphere incubator; inverted microscope; distiller; deionizers; warming oven; $8{ }^{\circ} \mathrm{C}$ and $-80{ }^{\circ} \mathrm{C}$ freezers and cell defrosting system were employed with their auxiliary instrumentations, including disposable materials from Sigma-Aldrich. Complete RPMI-1640 (RPMI) with L-glutamine and glucose-free (Sigma-Aldrich), fetal bovine serum (FBS) and phosphate buffered isotonic saline solution (PBS) were used. PBS buffer contains sodium chloride, sodium phosphate, potassium chloride, and potassium phosphate, for keeping the neutral $\mathrm{pH}$ of the solution prepared in distilled and deionized water. Human breast carcinoma lineage c231 was donated by Dr. Mirian Paz from the Pharmacology Department of Institute of Biological Sciences - ICB/UFMG. The MDA-MB-231 cell line of breast adenocarcinoma has epithelial morphology, derived from a metastatic site. Anhydrous D-glucose P.A.-A.C.S (Synth), coin Glu, and $\mathrm{GdCl}_{3} \cdot 6 \mathrm{H}_{2} \mathrm{O}$ with $99.8 \%$ purity from Sigma-Aldrich (CAS 13450-84-5). 


\section{Gd-Glu solution preparation}

Distilled and deionized water was used in the preparation of the aqueous solutions of gadolinium chloride and glucose. An amount of each primary solution was mixed, in order to have $1.0 \mathrm{mmol} \mathrm{L}^{-1}$ of Gd: Glu solution with a molar ratio of $1: 1$. The Gd-Glu solution was prepared and kept at $8^{\circ} \mathrm{C}$.

\section{Lineage in vitro - establishment and maintenance}

Cell cultures of MDA-MB-231 were maintained in RPMI supplemented with $10 \%$ FBS and gentamicin $\left(50 \mu \mathrm{g} \cdot \mu \mathrm{L}^{-1}\right)$ and streptomycin $\left(500 \mu \mathrm{g} \cdot \mu \mathrm{L}^{-1}\right)$ antibiotics, named complete M-medium. The T-75 culture flasks were filled up to $10 \mathrm{~mL} \mathrm{M-medium} \mathrm{and} \mathrm{placed} \mathrm{in} \mathrm{an} \mathrm{incubator}$ in $5 \% \mathrm{CO}_{2}$ at $37^{\circ} \mathrm{C}$, humid atmosphere. The cells were grown to $80 \%$ of confluence in the T-75 culture flasks.

\section{T-25 cell sample preparations}

Cells in a T-75 confluent bottle were detached with the trypsin-EDTA solution (Sigma), and then suspended and transferred to a $15 \mathrm{~mL}$ Falcon tube. The content was centrifuged and the complete M-medium was removed. The cell pellet was resuspended in with PBS. An aliquot was removed to be counted in Hemocytometer. Two aliquots with $2 \times 10^{6}$ cell were transferred to two T-25 flasks and fulfilled up to $2.5 \mathrm{~mL} \mathrm{PBS}$, and returned to the incubator for $2 \mathrm{~h}$. The cells were kept under glucose deprivation, seeking to reproduce a condition similar to that specified in PET-FDG human's protocols of $24 \mathrm{~h}$ with no exercise, no carbohydrates, $40 \%$ of normal daily water consumption, and $6 \mathrm{~h}$ total fasting prior exams.

\section{Group settings}

Three groups were set up: two control groups and one Glu-metal incubation group. The control groups were: zero control (Zero-control) that means T-flasks with cells without glucose or metal presence; metal control group (Metal-control) without glucose but incubated with the metal solution. And finally, the Glu-metal group was set to measure the metal uptake in specific incubation times of 30 and 50 min, with Glu-Gd in PBS. Figure 1A illustrates the number of culture flasks provided for each group: zero-control group with 2 flasks, metal-control group with 3 flasks, a group for the specific time study with 3 flasks. In addition, Figure 1B illustrates the protocols used to prepare the samples for NAA analysis in the reactor.

\section{Time kinetics of the exposition of the complex's solution}

An amount of Gd-Glu solution was added to each of the three T-25 flasks separately, such that $361.5 \mu \mathrm{g}$ of Gd metal was present in each flask with PBS solution. The flasks were nicely shook-up. The T-25 flasks were returned

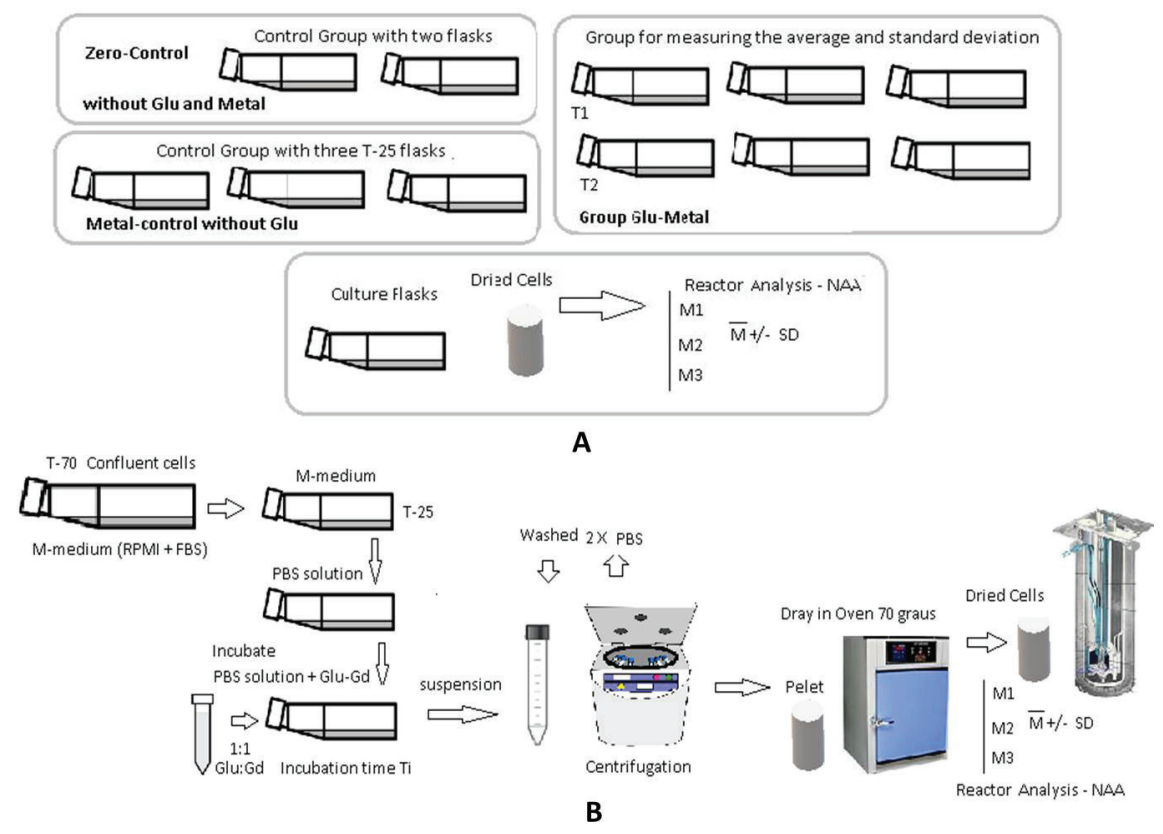

FIGURE 1 - (A) Representation of the flasks in the control groups (metal-control and zero control), and in the groups with glucosemetal incubation; (B) Illustration of the procedures used for measuring the metal concentration in dried samples, for each culture flask related to a specific incubation time. 
to the incubator and kept in the incubator. The times 30 and $50 \mathrm{~min}$ were established for the study.

\section{A collection of cell samples for NNA}

After the Gd-Glu incubation times, cells in T-25 flasks were suspended through vigorous refluxes, without the use of the trypsin-EDTA solution, and the cell suspension transferred to falcon tubes. The tubes were centrifuged to pellet formation, then resuspended and washed with 2.0 mL PBS buffer once; centrifuged, buffer removed and resuspended again with $500 \mu \mathrm{L}$ PBS buffer. Thus, the 500 $\mu \mathrm{L}$ aliquots of the whole cell suspension were transferred to a polyethylene vial and kept under incubator for $1 \mathrm{~h}$ to wait for the suspension of cells to precipitate on the bottom of the vial. Later, the vials were transferred to a warming drawer at $70^{\circ} \mathrm{C}$ for $1 \mathrm{~h}$. The solution was dried, generating a thin film on the bottom of the vial, containing a residual mass of cells that had been incubated to Gd-Glu at a specific time exposure, together with the phosphate buffer resides. Each vial represented a time of 30 or $50 \mathrm{~min}$, exposed to that $361.5 \mu \mathrm{g}$ of Gd metal available on the Gd-Glu solution. The vials held the cells and PBS buffer residues.

\section{Nuclear Analyze Activation - NAA method and concentration's evaluations}

The TRIGA MARK I IPR-R1 research reactor, CDTN/CNEN, Belo Horizonte, was used for NAA. The $\mathrm{k} 0$-method was used for neutron activation analysis since it excludes the needs of standards for the elements in the analysis (De Corte, 1986). The thermal neutron flux at $100 \mathrm{~kW}$ was about $6.35 .10^{11} \mathrm{n} \mathrm{cm}^{-2} \mathrm{~s}^{-1}$, the irradiation time was $8 \mathrm{~h}$, and the main parameters of the $\mathrm{k} 0$-method had been $\mathrm{f}=22,32$ and $\alpha=-0,0022$ (De Corte, 1986), relative to the PI-7 irradiation position (Menezes, Jacimovic, 2006). The masses of the samples had been surveyed conditioned in the flasks-A. As an internal control, two certified samples as reference were analyzed. After the irradiation, the activities and the spectrum of the samples had been analyzed in the gamma spectrometry system coupled to an HPGe gamma detector and associated electronics, together with the Genie 2000, CANBERRA, software for spectra acquisition. The spectra had been analyzed in the program HyperLab ${ }^{\circledR}$ and the elemental concentrations had been calculated in the Kayzero code for Windows ${ }^{\circledR}$.

\section{Mass spectrometry}

Aliquots of Gd-Glu solution were analyzed by ESI-MS, conducted in an LCQFleet mass spectrometer,
ThermoElectron. The electrospray source conditions were as follows: positive mode; spray voltage $5 \mathrm{kV}$, capillary voltage $36 \mathrm{~V}$, tube lens voltage $65 \mathrm{~V}$ sheath gas flow rate $\left(\mathrm{N}_{2}\right) 8$ bar, and capillary temperature $275^{\circ} \mathrm{C}$. The $\mathrm{m} / \mathrm{z}$ range analyzed was 50-2000. The samples were introduced directly in the electrospray source at $20 \mu \mathrm{L} \mathrm{min}^{-1}$ using a syringe pump.

\section{Statistical analysis}

The t-Student's T-test was used to obtain the significant difference between the average and standard deviation values obtained in the measurements. A significance level of 0.05 was adopted.

\section{RESULTS}

\section{In vivo uptake in cancer cells}

The recovered masses of $\mathrm{Na}, \mathrm{Cr}, \mathrm{Br}$, and $\mathrm{Gd}$ in dried samples of $\mathrm{c} 231$ cells were measured in the control condition. The presence of $\mathrm{Na}, \mathrm{Cr}$ and $\mathrm{Br}$ elements in all samples was observed; however, these were not shown. The $\mathrm{Na}, \mathrm{Br}$ and $\mathrm{Cr}$ metal masses found in NAA were possible due to contaminations from PBS buffer components; thus they were not from Gd-Glu exposition. A Gd mass was not identified in the Zero-control samples that mean values lower than the detectable mass.

The Gd recovered mass in the dried samples of c231 cells exposed to that $361.5 \mu \mathrm{g}$ of Gd in Glu-Gd solution in $3.0 \mathrm{~mL}$ PBS were $13.3 \pm 0.8$ and $12.5 \pm 0.7 \mu \mathrm{g}$, in times of 30 and 50 min of incubation to the Gd-Glu compound. The metal mass concentrations are shown in Table I. The coordination compound uptake was independent of the exposure time of the Gd-Glu solution in the intervals of 30 and 50 min incubation time since there is no significant statistical difference in those values.

Table I presents the measurements of the metal concentrations per dried cell masses in each specified experimental group. The $n . d$ means undetectable metal at Zero-group condition, which means that the metal concentrations were lower in dried cells than the detectable limits in NAA. There were statistically different between M-control group and data from the group with a metalglucose presence (Gd-Glu) at the time of $50 \mathrm{~min}$.

\section{Complex formation and characterization}

Figure 2 depicted the ESI-MS spectrum of the Gd-Glu solution. The sets of ions centered at the $\mathrm{m} / \mathrm{z}$ of 516, 552, 696 and 923 were assigned to positively 
TABLE I - Metal mass concentrations, in $\mu \mathrm{g} \cdot \mathrm{g}^{-1}$, of dried cell mass at the three groups: Zero-control, M-control, and Gd-Glu for incubation times of 30 and $50 \mathrm{~min}$.

\begin{tabular}{lcc}
\hline Group & \multicolumn{2}{c}{ Incubation time $[\mathbf{m i n}]$} \\
\cline { 2 - 3 } Specification & $\mathbf{3 0}$ & $\mathbf{5 0}$ \\
\hline Zero-control & $0.0($ n.d $)$ & $0.0($ n.d $)$ \\
M-control & - & $2780 \pm 440(\mathrm{Uc})$ \\
Gd-Glu group & $13404 \pm 2104$ & $11347 \pm 2742$ \\
\hline
\end{tabular}

species containing $\mathrm{Gd}^{+3}$, glucose molecules (neutral or deprotonated) and chloride ions. Salpin and Tortajada, 2003, had already reported the deprotonation of the glucose-lead complex under the ESI-MS conditions (Salpin, Tortajada, 2003).

Based on similar Salpin and Tortajada analyses, our findings can point to the formation of $\mathrm{C}_{12} \mathrm{H}_{22} \mathrm{O}_{12} \mathrm{Gd}$, $\mathrm{C}_{12} \mathrm{H}_{23} \mathrm{O}_{12} \mathrm{GdCl}, \mathrm{C}_{18} \mathrm{H}_{34} \mathrm{O}_{18} \mathrm{Gd}, \mathrm{C}_{18} \mathrm{H}_{33} \mathrm{O}_{18} \mathrm{Gd}_{2} \mathrm{Cl}_{2}$ complexes in solution. The nominal masses, evaluated to the theoretical assignment of the chemical formulae, were presented in Table II. The $\mathrm{m} / \mathrm{z}$ experimental signals were found equivalent to the $\mathrm{m} / \mathrm{z}$ theoretical signals of the assignment chemical formulae, based on Isotope Pattern Calculator, taken into consideration the uncertainty of the measurements in ESI-MS experiments (ChemPuter, 2017).

Gadolinium presents six stable isotopes $\left[{ }^{154} \mathrm{Gd}\right.$ $(2.18 \%),{ }^{155} \mathrm{Gd}(14.80 \%),{ }^{156} \mathrm{Gd}(20.47 \%),{ }^{157} \mathrm{Gd}$ $(15.65 \%),{ }^{158} \mathrm{Gd}(24.84 \%)$ e $\left.{ }^{160} \mathrm{Gd}(21.86 \%)\right]$. Five stable isotopes with abundance higher than $10 \%(155,156$, 157,158 and 160) generating isotopic standards with five signs with large abundance. Those signs were associated with groups of isotopologues, i.e., molecules that differ only in their isotopic composition, resulting from coordination between the metal and the glucose neutral or deprotonated, in addition to chlorine, in some of the species in their respective mass spectra. As shown in Figures 2 and 3, the theoretical mass spectra of the proposed species were obtained and the resulting isotopic patterns held their similar correspondences with the experimental spectra.

TABLE II -Attributions of the $\mathrm{m} / \mathrm{z}$ signals in the spectrum of the Gd-Glu solution, the relative abundance in ESI-MS, the specification of theoretical assignment of the chemical formula, nominal mass (a.m.u) estimation and possible ion species in the complex formation

\begin{tabular}{ccccc}
\hline$m / z$ & Relative Abundance (\%) & Theoretical assignment & MW (a.m.u) & Proposed species \\
\hline 516 & 26 & $\mathrm{C}_{12} \mathrm{H}_{22} \mathrm{O}_{12} \mathrm{Gd}$ & 515.54 & {$\left[\mathrm{Gd}(\mathrm{Glu})_{2}-2 \mathrm{H}\right]^{+}$} \\
552 & 100 & $\mathrm{C}_{12} \mathrm{H}_{23} \mathrm{O}_{12} \mathrm{GdCl}$ & 552.00 & {$\left[\mathrm{Gd}(\mathrm{Glu})_{2} \mathrm{Cl}-\mathrm{H}\right]^{+}$} \\
696 & 34 & $\mathrm{C}_{18} \mathrm{H}_{34} \mathrm{O}_{18} \mathrm{Gd}$ & 695.69 & {$\left[\mathrm{Gd}(\mathrm{Glu})_{3}-2 \mathrm{H}\right]^{+}$} \\
923 & 12 & $\mathrm{C}_{18} \mathrm{H}_{33} \mathrm{O}_{18} \mathrm{Gd}_{2} \mathrm{Cl}_{2}$ & 922.84 & {$\left[\mathrm{Gd}_{2}(\mathrm{Glu})_{2} \mathrm{Cl}_{2}-3 \mathrm{H}\right]^{+}$} \\
\hline
\end{tabular}

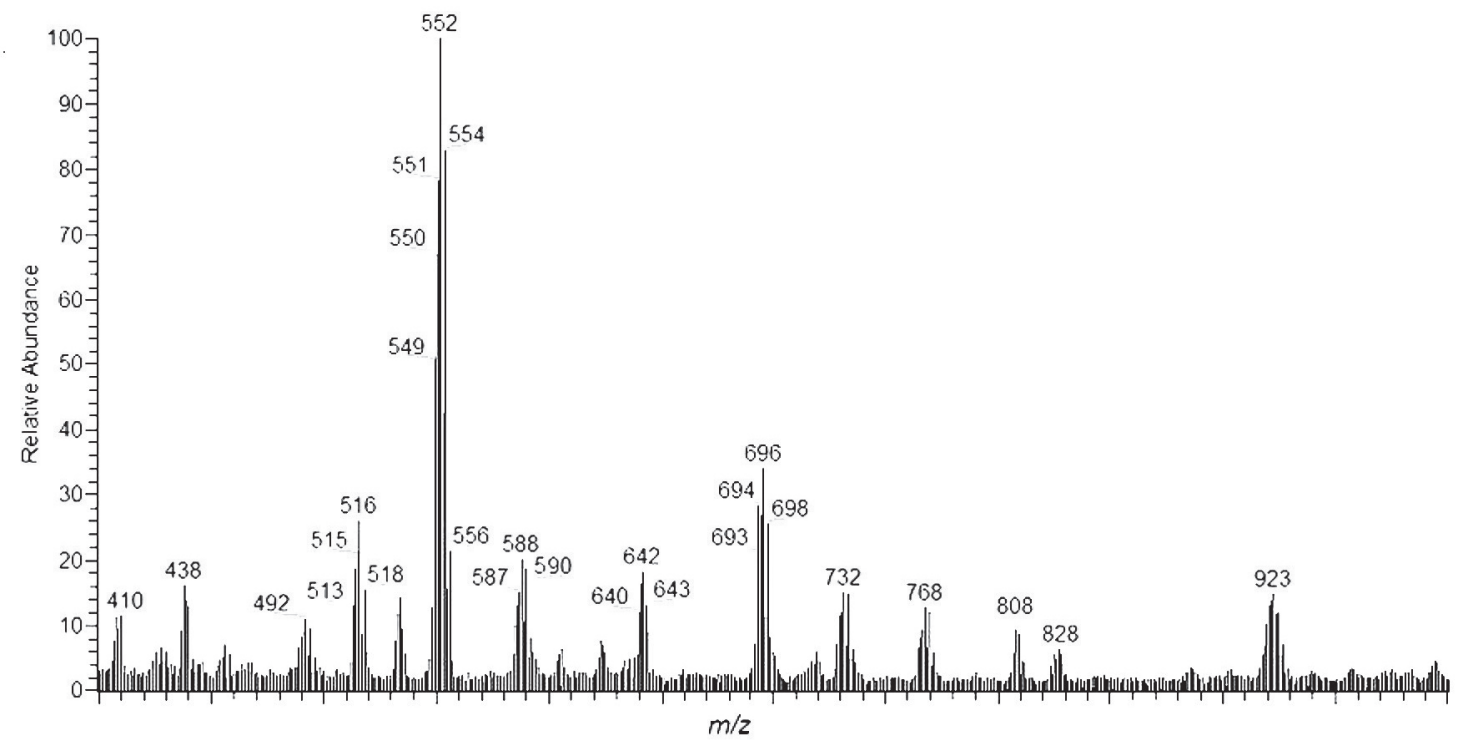

FIGURE 2 - The ESI-MS spectrum of the solutions of Gd-Glu solution, depicting relative abundances as a function of $\mathrm{m} / z$ at the 400 to 1100 range. 

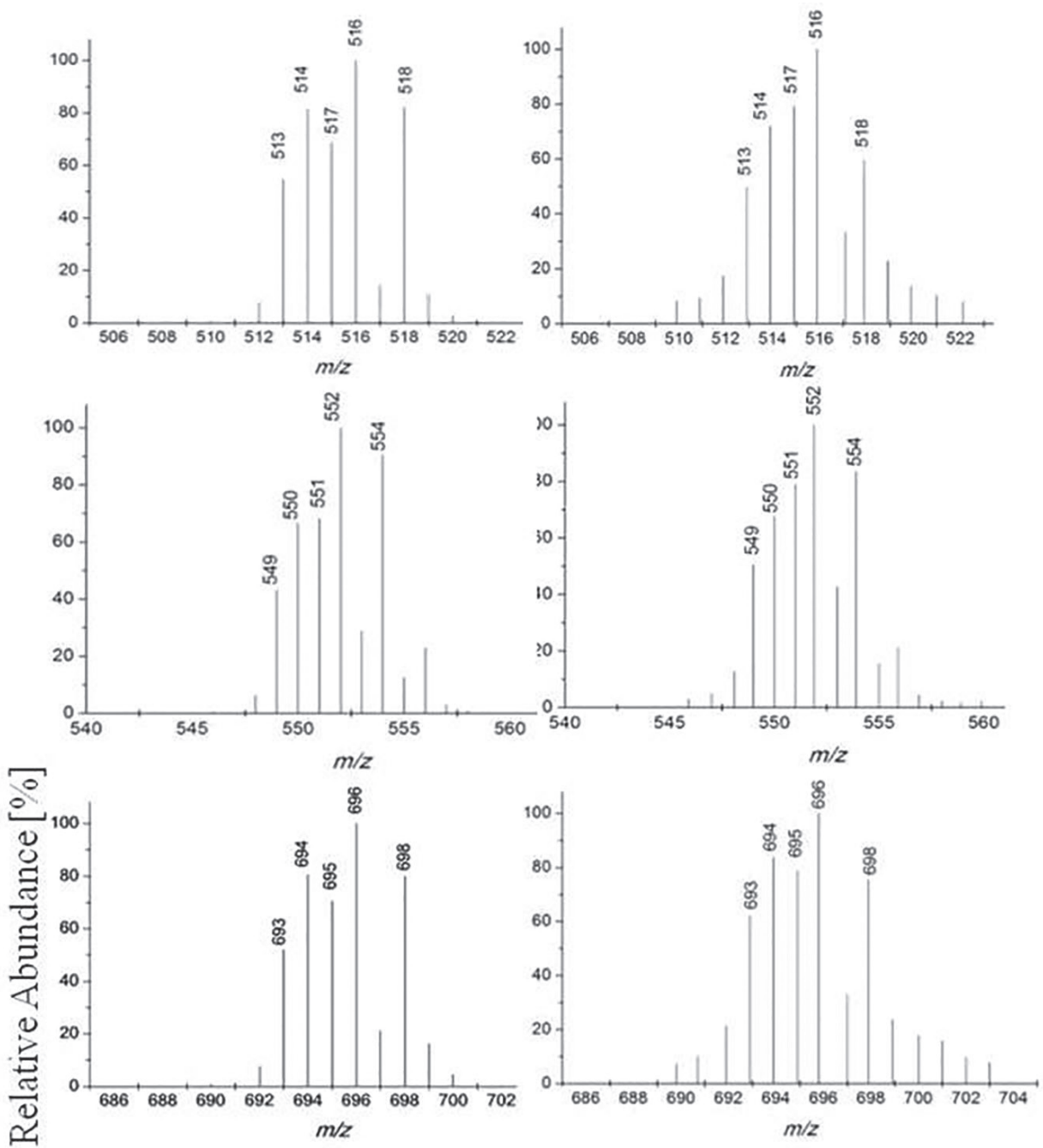

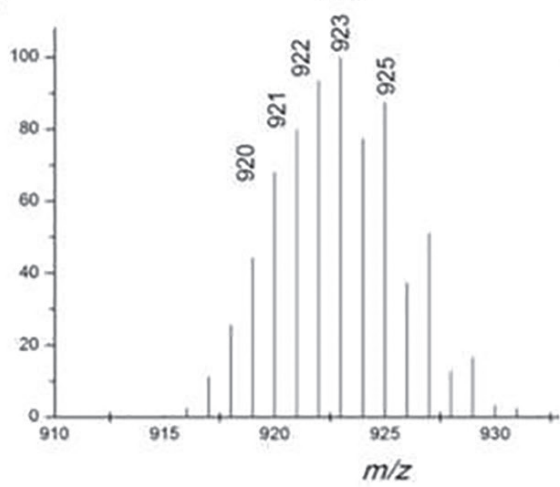

A. Theoretical

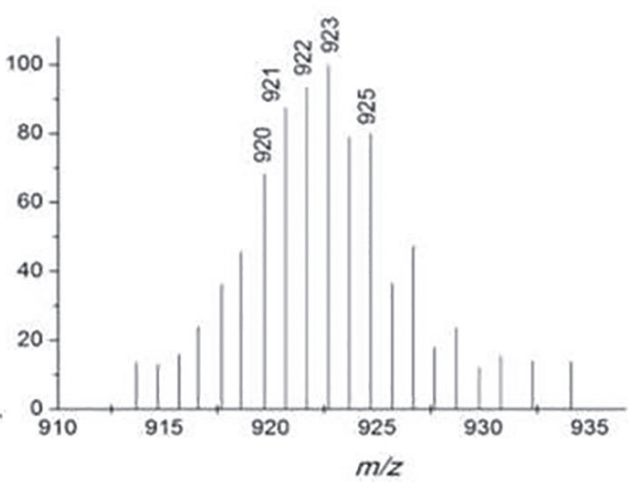

B. Experimental

FIGURE 3 - (A) theoretical mass spectra and (B) experimental mass spectra of the Gd-Glu solution in the regions of $\mathrm{m} / \mathrm{z}$ : 516 to $\mathrm{C}_{12} \mathrm{H}_{22} \mathrm{O}_{12} \mathrm{Gd} ; 552$ to $\mathrm{C}_{12} \mathrm{H}_{23} \mathrm{O}_{12} \mathrm{GdCl} ; 696$ to $\mathrm{C}_{18} \mathrm{H}_{34} \mathrm{O}_{18} \mathrm{Gd}$; and 923 to $\mathrm{C}_{18} \mathrm{H}_{33} \mathrm{O}_{18} \mathrm{Gd}_{2} \mathrm{Cl}_{2}$, respectively.

\section{DISCUSSION}

The cells were kept under glucose deprivation, seeking to reproduce a condition similar to that specified in PET-FDG human's protocol of $24 \mathrm{~h}$ with no exercise, no carbohydrates, $40 \%$ of normal daily water consumption, and $6 \mathrm{~h}$ total fasting prior exams.

The present in vitro experiment favors the passive transport of glucose, given the lack of hormones on which the active process depends on, and the differential metal 
concentrations of glucose-deprivation in the cytoplasm cells and in the solution. Therefore, despite the glucose deprivation condition, the transport of Gd-Glu through the cell membrane uses physiological mechanisms of internalization.

The metal uptake in c231 in PBS, without glucose, is associated with the phosphate present in the buffer. There is a pharmacokinetic associated with this chelate, that is different from the influx time of glucose complexes. Phosphate transport through cellular membrane has already been described, including metal-phosphate influxes and effluxes. Phosphorylation of proteins is the addition of a phosphate group $\left(\mathrm{PO}_{4}^{-}\right)$to the polar group $\mathrm{R}$ of various amino acids. Therefore, the PBS buffer in the in vitro experiment was not an inert medium.

The preparation of the buffer of $1 \times$ PBS had a final concentration of $10 \mathrm{mM} \mathrm{PO}_{4}^{3-}, 137 \mathrm{mM} \mathrm{NaCl}$, and $2.7 \mathrm{mM}$ $\mathrm{KCl}$ per liter of deionized water. The findings appear to demonstrate that the free ions of $\mathrm{Gd}^{3+}$ can interact with $\mathrm{PO}_{4}{ }^{3-}$ anions in solution. In other words, $\mathrm{PO}_{4}{ }^{3-}$ anions can compete with $\mathrm{Gd}^{3+}$ in Glu-Gd complexes. It may reduce the uptake of glucose, especially in a $37^{\circ} \mathrm{C}$ hot medium, due to the trans-chelation processes. The amount of $10 \mathrm{mM}$ of $\mathrm{PO}_{4}{ }^{3-}$ held $6.0210^{+21}$ molecules of phosphate, while the experiment with glucose complexes held the amount of $4.3410^{+20}$ molecules of Glu-Gd complexes in the medium. Therefore, stoichiometric ratio of Glucomplexes per Phosphate-molecules was 1:14. The phosphate anions seem to compete in linking to $\mathrm{Gd}$ in a greater numerical advantage of 14 -folds. In addition, the M-control experiment used of $1 \mathrm{~mL}$ of trypsin/EDTA to help in detaching the cells from the flasks; therefore, $\mathrm{Gd}^{3+}$ ions were also exposed to the EDTA chelate. Both, EDTA and Phosphate may help the internalization of the metal to the cancer cells, following different routes than glucose. Although these facts were relevant, the concentration at Glu-Gd group was statistically different and higher than $\mathrm{M}$-control, demonstrate that glucose-metal is specific and provide a higher uptake than M-control, despite the possible chelates' competition.

The use of trypsin to cell detaching from flasks has been demonstrated to produce a high leakage of metabolites (Bi et al., 2013). The kinetic time of this trypsin-effect is unknown; thus, it may influence the short-time of Glu c231-uptake. It was the reason for the no use of trypsin in the cell culture that was incubated with Gd-Glu, in the Gd-Glu group, as described in our experiment. However, the cell detachment of the T-25 flasks without trypsin could be compromised, and not all cells were removed and included in the NAA analysis.
The complete M-medium was prepared with RPMI-1640, poor in glucose, however, supplemented with L-glutamine. L-glutamine is significantly incorporated by c231 as a requirement to cell survival and proliferation (Long, Li, Zhang, 2016; Falcão et al., 2015).

Glucose and Glutamine are relevant nutrients enrolled in key metabolic pathways (Wise, Thompson, 2010). Since c 231 does not produce estrogen, progesterone and human epidermal growth factor receptor 2 (HER2) receptors, thus c231 line is considered a triple-negative breast cancer cell which has a high probability of therapy failure (André, Zielinski, 2012). The information on Gd-Glu uptake in the triple-negative c231 is relevant; however, in our study, no comparison with another cell line with positive receptors has been addressed yet.

Glucose was absent in the M-medium used for the cell grown, and in the PBS solution for the experimental conditions. Glucose was only present when cells were incubated with Glu-Gd, added in the PBS solution.

Peterson et al. (2016), demonstrated that $\mathrm{c} 231$ incorporates glucose into the glycolytic pathways (GP) and shows that the GP was highly active at $60 \mathrm{~min}$ Glu incubation (Peterson et al., 2016). Our data showed similar time Gd-Glu uptakes, at 30 and $50 \mathrm{~min}$, in comparison to Peterson and cols information. The amount of Gd available in the solution $(361.5 \mu \mathrm{g}$ of $\mathrm{Gd}$ in $3.0 \mathrm{~mL})$ was chosen in similarity with a usual boron concentration in blood in BPA I.V. application in BNCT in vivo experiments (Brandão, Campos, 2015).

A large amount of $\mathrm{Gd}$ in blood is expected if we consider the amount of $\mathrm{Gd}$ in a contrast agent. There is no agreement about the optimal blood concentration of gadolinium-based contrast agents. Diagnosis is usually performed with $1 \mathrm{M}$ of $\mathrm{Gd}$ agent. As an example, 20 $\mathrm{mL}$ of Gadodiamide, $\mathrm{C}_{16} \mathrm{H}_{26} \mathrm{GdN}_{5} \mathrm{O}_{8}$ of molecular weight $573.661{\mathrm{~g} . \mathrm{mol}^{-1}}^{-1}$, is applied in an MRI exam with $287 \mathrm{mg} . \mathrm{mL}^{-1}$, or $5.74 \mathrm{~g}$ of Gd in $\sim 5.0 \mathrm{~L}$ of blood. Therefore, a blood concentration of $1.15 \mathrm{mg} \cdot \mathrm{mL}^{-1}$ of gadolinium $\left(1150 \mu \mathrm{g} \mathrm{mL}^{-1}\right)$ is present in a gadolinium-based contrast MR imaging. Such value represents 9.6-folds the solution concentration in our cell uptake assay.

The present time kinetic experiment at 50 min was out of the ideal time of the pharmacokinetics of the glucose that has a quick uptake. Indeed, it is expected a lower concentration of Gd-Glu at $1 \mathrm{~h}$ post-injection. However, MRI imaging requires time to have a suitable T1-image with contrast. Better and fast protocols for Gd-Glu contrast shall be discussed and defined later.

Molecular trapping mechanisms similar to ${ }^{18} \mathrm{~F}-\mathrm{FDG}$ are unpredictable to Glu-Gd at present. However, specific mechanisms of metal effluxes of mammalian cells are 
unknown; therefore, one can suppose that after lanthanide internalization such chemical element could be trapped into the cell.

Gadolinium is not a neutron atom in solution. Small ionic radii are expected in the $\mathrm{Ln}^{+3}$ ions of lanthanide in water solution. The lanthanides Sm, Eu, Gd Tb, Dy, and Ho have similar ionic radii, varying from 95.8 to $90.1 \mathrm{pm}$; 1.5 times smaller than oxygen anions. Lanthanides also have similar primary valence. In addition, Gd has an atomic electron configuration of $[\mathrm{Xe}] 4 \mathrm{f}^{7} 5 \mathrm{~d}^{1} 6 \mathrm{~s}^{2}$. The $\mathrm{Gd}$ as a coordination center in the Glu-Gd complexes attends its primary valence and its secondary valence, filling the fand $\mathrm{d}$ subshells, toward the configuration of the Rn noble gas. It means Gd can receive various pairs of electrons of the Gluligands fulfilling the $4 \mathrm{f}$ and latter $5 \mathrm{~d}$ subshells, driving the electronic configuration toward the radon chemical element.

Glucose uptake in cells is well-described in literature, limited to the passive diffusion and active processes. The facilitated diffusion is supported by GLUT transporters, while primary and secondary active transports are going against the gradient of glucose concentration. In our experiment, the condition of holding the cells for a long period in a poor Glu concentration medium, provide an environment for the passive transport being acting. Therefore, it is a possibility that passive transport is responsible for the metal uptake in c231 cells in the present in vitro assay. However, none can be said about the possibility of active transport of Gd-Glu, that shall be studied later.

The analogs of glucose as 5-thio-glucose and 1-betaD-glucose linked to metals has already been tested in vitro and later demonstrated uptake in inflammations in animal models, statistically different than control (Campos, Dalmazio, 2010; Campos, Brasileiro, Maia, 2009). Also, in nature, It has already proved that glucose helps metal uptake in yeast, bacteria, and plants (Gomes et al., 2002). In general, in vitro experiments provide good pharmaceutical information that correlates to human. Indeed, in vitro tests have been improved and became an alternative to animal testing by the pharmaceutical industry (Goh et al., 2013). Therefore, one can expect that Gd-Glu uptake in vitro can happen in vivo, under physiological condition. In blood, many other substances are present, including natural chelates and proteins that carry metal, as Ferritin, in which transchelation can also occur. Further analysis of Gd-Glu uptake in vivo shall be later present.

Sugar bound nanoparticles (NP) have already been investigated (Geng et al., 2011). Geng and cols reported that thio-glucose bound gold nanoparticle (Glu-GNPs) resulted in an approximate $31 \%$ increase in nanoparticle uptake compared to naked GNPs, with the ovarian cell in vitro studies (Geng et al., 2011). However, Glu-GNP concentration in cells achieved maximum at $24-48 \mathrm{~h}$ of incubation time in an amount of 8 -folds than uptake at $4 \mathrm{~h}$, in a time period of $2 \mathrm{~h}$ to $96 \mathrm{~h}$ of incubation time. In relation to our study, large Gd-uptake occurred in 30-50 min after exposition; while Glu-GNP occurred in $24-48 \mathrm{~h}$ of continuing incubation. Differences in the uptake time are relevant to a possible MRI procedure.

Shan et al. (2016) reported the evaluation of the effect of dimercaptosuccinic acid (DMSA)coated superparamagnetic iron oxide nanoparticles, $\gamma-\mathrm{Fe}_{2} \mathrm{O}_{3} @$ DMSA (NPS), bearing the 2-deoxy-D-glucose (2-DG) binder on targeting tumors with high-Glu metabolism. (Shan et al., 2016) In vitro, there was a significant uptake of NPS-DG by MDA-MB-231 and MCF-7 cells; however, glucose inhibited the NPS uptake after cell Glucose previous exposition within $2 \mathrm{~h}$. Uptake of NPS-DG was significantly higher in MDA-MB-231 compared with MCF-7 cells. In vivo, NPS-DG could be detected in the liver and in tumors post-injection, which can be assessed by magnetic resonance imaging. Our study addressed only in vitro study. It will be a challenge to compare Gd-Glu with Glu-NPS at in vivo MRI.

The methods of characterization of coordination compounds with electrospray ionization mass spectrometry (ESI-MS) can be employed accurately in assessing the masses of the possible coordinated compounds. ESI-MS has mainly been employed in the analysis of biomolecules and the characterization of unstable species. The electrospray ionization is a soft ionization technique that has the ability to transfer ions directly from solution to the gas phase and thus allow the analysis by mass spectrometry, making it an ideal instrument for the study of ionic compounds. For this reason, the use of ESI-MS has been increased on the structural characterization of organometallic and coordination compounds (Cooks et al., 2006). The chemical compounds of high abundances in the ESI-MS were the following: $\mathrm{C}_{12} \mathrm{H}_{23} \mathrm{O}_{12} \mathrm{GdCl}(100 \%)$, $\mathrm{C}_{18} \mathrm{H}_{34} \mathrm{O}_{18} \mathrm{Gd}(34 \%)$ and $\mathrm{C}_{12} \mathrm{H}_{22} \mathrm{O}_{12} \mathrm{Gd}(26 \%)$, which refer to the ions centered at $\mathrm{m} / \mathrm{z}$ of 552,696 and 516. The ESI-MS data demonstrated that the complex formed by two Glu-molecule ligands bound to Gd stabilized by one $\mathrm{Cl}^{-}$anion has the highest probability to be generated in an aqueous solution. However, such abundance must also be verified in vivo, out of the ESI-MS environment.

In conclusion, experiment with the metal-control group was performed in the PBS buffer solution; however, due to the presence of phosphate in solution, internalization of the metal in the c231 cells was observed. Therefore, the PBS solution was not inert to gadolinium presence. Although, the uptake of Gd in the Glu-Gd group demonstrated to be 
statistically higher than zero-control and M-control groups. Consequently, there were metabolic gadolinium uptakes in breast cancer cells in vitro when exposed to Gd-Glu solution up to 30-50 min incubation time, providing a suitable cell uptake at a long time for a possible NMR image. It is possible to state that metal coordination with glucose helped the gadolinium uptake in the cancer cells. Characteristic $\mathrm{m} / \mathrm{z}$ ions in the ESI-MS reported the interaction of gadolinium and glucose in solution. The findings will drive the researchers to the study of the viability of in vivo magnetic resonance imaging employing the Gd-Glu complexes as a possible high-metabolic contrast-agent.

\section{ACKNOWLEDGMENTS}

Authors are thankful to the Spectrometric Laboratory at the Chemistry Department, Universidade Federal de Minas Gerais, due to the Mass Spectrometry measurements; Laboratory of Nuclear Reactor from Centro de Desenvolvimento de Tecnologia Nuclear - CDTN, who kindly pursued the Nuclear Activation Analysis. Authors are thankful to the Conselho National de Desenvolvimento da Ciência e Tecnologia (CNPq) by financial support, process 456719/2013-0 REBRAT -SUS at 2013.

\section{REFERENCES}

Abdou AG, Eldien MM, Elsakka D. GLUT-1 Expression in cutaneous basal and squamous cell carcinomas. Int J Surg Pathol. 2015;23(6):447-453.

André F, Zielinski CC. Optimal strategies for the treatment of metastatic triple-negative breast cancer with currently approved agents. Ann Oncol. 2012;23(Suppl 6):vi46-vi51.

Bache M, Rot S, Kessler J, Guttler A, Wichmann H, Greither $\mathrm{T}$, et al. mRNA expression levels of hypoxia-induced and stem cell-associated genes in human glioblastoma. Oncol Rep. 2015;33(6):3155-3161.

Bi H, Krausz KW, Manna SK, Li F, Johnson CH, Gonzalez FJ. Optimization of harvesting, extraction, and analytical protocols for uplc-esi-ms-based metabolomic analysis of adherent mammalian cancer cells. Anal Bioanal Chem. 2013;405(15):5279-5289.

Brandão S, Campos TPR. Intracavitary moderator balloon combined with ${ }^{252} \mathrm{Cf}$ brachytherapy and boron neutron capture therapy, improving dosimetry in brain tumor and infiltrations. Brit J Radiol. 2015;88(1051):20140829.
Campos TPR, Brasileiro CB, Maia MJO. radiofármaco e suas composições para cintilografia de sitios inflamatórios e infecciosos. PI 0904754-9 A2, Universidade Federal de Minas Gerais; 2009.

Campos TPR, Dalmazio I. Compostos de coordernação metal-sacarídeo para terapia e diagnóstico, PI 1005216-0 A2, Universidade Federal de Minas Gerais; 2010.

Cantuaria G, Fagotti A, Ferrandina G, Magalhaes A, Nadji M, Angioli R, et al. GLUT-1 expression in ovarian carcinoma: association with survival and response to chemotherapy. Cancer. 2001;92(5):1144-1150.

Chart of Nuclides. [accessed at 02-02-2017]. Available at: http:// www.nndc.bnl.gov/chart/.

ChemPuter. [accessed at 02-02-2017]. Available at: http://winter. group.shef.ac.uk/chemputer/isotopes.html.

Cooks RG, Ouyang Z, Takats Z, Wiseman JM. “Ambient Mass Spectrometry”. Science. 2006;311(5767):1566-1570.

De Corte F. The $\mathrm{k}_{0}$ - standardization method; A move to the optimization of neutron activation analysis, Ryksuniversiteit Gent, Faculteit Van de Wetenschappen; 1986.

Falcão PL, Motta BM, Lima FC, Vieira LC, Campos TPR. Aumento de viabilidade de clones radiossensível (PBMC) e resistente (MDA-MB-231) na cobaltoterapia em taxa de dose reduzida. Radiol Bras. 2015;48(3):158-165.

Gatenby RA, Gillies RJ. Why do cancers have high aerobic glycolysis? Nat Rev Cancer. 2004;4(11):891-899.

Geng F, Song K, Xing JZ, Yuan C, Yan S, Yang Q, et al. Thio-glucose bound gold nanoparticles enhance radiocytotoxic targeting of ovarian cancer. Nanotechnology. 2011;22(28):285101.

Goh JY, Weaver RJ, Dixon L, Platt NJ, Roberts RA. Development and use of in vitro alternatives to animal testing by the pharmaceutical industry 1980-2013. Toxicol. Res. 2015;4:12971307.

Gomes NCM, Rosa CA, Pimentel PF, Mendonça-Hagler LCS. Uptake of free and complexed silver ions by different strains of rhodotorula mucilaginosa. Braz J Microbiol. 2002;33(1):62-66. 
Guglielmo FF, Mitchell DG, Gupta S. Gadolinium contrast agent selection and optimal use for body MR imaging. Radiol Clin North Am. 2014;52(4):637-656.

Haber RS, Rathan A, Weiser KR, Pritsker A, Itzkowitz SH, Bodian C, et al. GLUT1 glucose transporter expression in colorectal carcinoma: a marker for poor prognosis. Cancer. 1998;83(1):34-40.

Justus C, Sanderlin E, Yang L. Molecular connections between cancer cell metabolism and the tumor microenvironment. Int $\mathrm{J}$ Mol Sci. 2015;16(5):11055-86.

Lide DR (editor-in-chief). CRC Handbook of Chemistry and Physics. 90th ed. Boca Raton: CRC Press; 2009.

Liu Y, Wu X, Sun X, Wang D, Zhong Y, Jiang D, et al. Design, synthesis, and evaluation of VEGFR-targeted macromolecular MRI contrast agent based on biotin-avidin-specific binding. Int J Nanomedicine. 2017;12:5039-5052.

Long J-P, Li X-N, Zhang F. Targeting metabolism in breast cancer: How far we can go? World J. Clin. Oncol. 2016;7(1):122130.

Manolescu AR, Witkowska K, Kinnaird A, Cessford T, Cheeseman C. Facilitated hexose transporters: new perspectives on form and function. Physiology (Bethesda). 2007;22:234-240.

Menezes MÂBC, Jacimovic R. Optimised $\mathrm{k}_{0}$-instrumental neutron activation method using the TRIGA MARK I IPR-R1 reactor at CDTN/CNEN. Belo Horizonte, Brazil. Nucl Instruments Meth Phys Res A. 2006;564:707-715.

Ngo H, Tortorella S, Ververis K. Karagiannis T. The warburg effect: Molecular aspects and therapeutic possibilities. Mol Biol Rep. 2015;42(4):825-834.

Ogawa J, Inoue H, Koide S. Glucose-transporter-type-I-gene amplification correlates with sialyl-Lewis-X synthesis and proliferation in lung cancer. Int J Cancer. 1997;74(2):189-192.

Peterson AL, Walker AK, Sloan EK, Creek DJ. Optimized method for untargeted metabolomics analysis of MDA-MB-231 breast cancer cells. Metabolites. 2016;6(4):E30.

Rammohan N, Holbrook RJ, Rotz MW, MacRenaris KW, Preslar AT, Carney CE, et al. Gd(III)-gold nanoconjugates provide remarkable cell labeling for high field magnetic resonance imaging. Bioconjug Chem. 2017;28(1):153-160.
Rogers S, Macheda ML, Docherty SE, Carty MD, Henderson MA, Soeller WC, et al. Identification of a novel glucose transporter-like protein-GLUT-12. Am J Physiol Endocrinol Metab. 2002;282(3):E733-E738.

Salpin JY, Tortajada J. Gas-phase reactivity of lead(II) ions with D-glucose. Combined electrospray ionization mass spectrometry and theoretical study. J Phys Chem A. 2003;107(16):2943-53.

Shah N, Sattar A, Benanti M, Hollander S, Cheuck, L. Magnetic resonance spectroscopy as an imaging tool for cancer: a review of the literature. J Am Osteopath Assoc. 2006;106(1):23-27.

Shan XH, Wang P, Xiong F, Gu N, Hu H, Qian W, et al. MRI of high-glucose metabolism tumors: a study in cells and mice with 2-DG-modified superparamagnetic iron oxide nanoparticles. Mol Imaging Biol. 2016;18:24-33.

Uldry M, Thorens B. The SLC2 family of facilitated hexose and polyol transporters. Pflügers Arch. 2004;447(5):480-489.

Van de Nes JA, Griewank KG, Schmid KW, Grabellus F. Immunocytochemical analysis of glucose transporter protein-1 (GLUT-1) in typical, brain invasive, atypical and anaplastic meningioma. Neuropathology. 2015;35(1):24-36.

Warburg O, Wind F, Negelein E. The metabolism of tumors in the body. J Gen Physiol. 1927;8(6):519-530.

Wise DR, Thompson CB. Glutamine addiction: A new therapeutic target in cancer. Trends Biochem Sci. 2010;35(8):427-433.

Younes M, Brown RW, Mody DR, Fernandez L, Laucirica R. GLUT1 expression in human breast carcinoma: correlation with known prognostic markers. Anticancer Res. 1995;15(6B):28952898.

Younes M, Lechago LV, Somoano JR, Mosharaf M, Lechago J. Immunohistochemical detection of Glut3 in human tumors and normal tissues. Anticancer Res. 1997;17(4A):2747-2750.

Zamora-Leon SP, Golde DW, Concha II, Rivas CI, DelgadoLopez F, Baselga J, et al. Expression of the fructose transporter GLUT5 in human breast cancer. Proc Natl Acad Sci USA. 1996;93(5):1847-1852.

Received for publication on $02^{\text {nd }}$ July 2018 Accepted for publication on $10^{\text {th }}$ October 2018 